\title{
IL-17-producing NKT cells depend exclusively on IL-7 for homeostasis and survival
}

\author{
KE Webster ${ }^{1,2}$, H-O Kim ${ }^{1}$, K Kyparissoudis ${ }^{3}$, TM Corpuz ${ }^{1}$, GV Pinget ${ }^{1}$, AP Uldrich ${ }^{3}$, R Brink ${ }^{1,2}$, \\ GT Belz ${ }^{4,5}$, J-H Cho ${ }^{1,2}$, DI Godfrey ${ }^{3}$ and J Sprent ${ }^{1,2,6}$
}

Natural killer T (NKT) cells are innate-like T cells that rapidly recognize pathogens and produce cytokines that shape the ensuing immune response. IL-17-producing NKT cells are enriched in barrier tissues, such as the lung, skin, and peripheral lymph nodes, and the factors that maintain this population in the periphery have not been elucidated. Here we show that NKT17 cells deviate from other NKT cells in their survival requirements. In contrast to conventional NKT cells that are maintained by IL-15, ROR $\gamma \mathrm{t}^{+}$NKTcells are IL-15 independent and instead rely completely on IL-7. IL-7 initiates a T-cell receptor-independent (TCR-independent) expansion of NKT17 cells, thus supporting their homeostasis. Without IL-7, survival is dramatically impaired, yet residual cells remain lineage committed with no downregulation of ROR $\gamma \mathrm{t}$ evident. Their preferential response to IL-7 does not reflect enhanced signaling through STAT proteins, but instead is modulated via the PI3K/AKT/mTOR signaling pathway. The ability to compete for IL-7 is dependent on high-density IL-7 receptor expression, which would promote uptake of low levels of IL-7 produced in the non-lymphoid sites of lung and skin. This dependence on IL-7 is also reported for ROR $\gamma \mathrm{t}^{+}$innate lymphoid cells and CD4 ${ }^{+}$Th17 cells, and suggests common survival requirements for functionally similar cells.

\section{INTRODUCTION}

Natural killer T (NKT) cells are lipid antigen-reactive, CD1drestricted $\mathrm{T}$ cells that represent a unique and critical element of the immune repertoire. They respond swiftly to pathogens, either by direct recognition of bacterial glycolipid antigen ${ }^{1}$ or indirectly via cytokine and self-lipid antigen ligation ${ }^{2,3}$ and rapidly produce a range of cytokines that can dictate the course of the subsequent immune response.

It has long been known that the range of cytokines produced by NKT cells is exceptionally diverse. More recently, it was observed that they can produce IL-17, a cytokine crucial for host defence against bacterial and fungal infections. ${ }^{4-7}$ These NKT17 cells constitutively express the transcription factor retinoic acid receptor-related orphan receptor $\gamma \mathrm{t}(\mathrm{ROR} \gamma \mathrm{t})$, are NK1.1 negative, and respond to IL- $1 \beta$ and IL- 23 by upregulating IL-17. ${ }^{7-9}$ Unlike conventional NKT cells, NKT17 cells are enriched in "gateway" tissues such as the lung, skin, and peripheral lymph nodes (pLN), with lower proportions in the spleen and liver, ${ }^{5,8}$ making them well-placed to respond early to a pathogenic insult.

That IL-17 is of clinical importance is now clear, ${ }^{10}$ and a role for IL-17-producing NKT cells is now emerging, particularly in the lung. NKT cells have been found to recognize glycolipids from Streptococcus pneumonia, the leading cause of community-acquired pneumonia, and can make IL-17 rapidly in response. ${ }^{1}$ There is also evidence they have a key role in ozoneinduced asthma, with both IL-17 and NKT cells required for the airway hyperactivity produced under these conditions. ${ }^{11}$ In addition, experimental data indicates a potential role in autoimmune disease, with NKT cells, along with other innate-like $\mathrm{T}$ cells, producing a significant proportion of the early IL-17 in the mouse model of multiple sclerosis. ${ }^{12}$

NKT17 cells acquire ROR $\gamma \mathrm{t}$ expression in the thymus, ${ }^{13}$ where their developmental decisions are mediated by low expression of Th-POK and SMAD4-dependent TGF $\beta$ signaling. ${ }^{14-16}$ That NKT17 cells follow distinct developmental

\footnotetext{
Immunology Division, Garvan Institute of Medical Research, Darlinghurst, Australia. ${ }^{2}$ St Vincent's Clinical School, University of New South Wales, Sydney, Australia. ${ }^{3}$ Department of Microbiology and Immunology, University of Melbourne, Parkville, Australia. ${ }^{4}$ Molecular Immunology Division, The Walter and Eliza Hall Institute of Medical Research, Parkville, Australia. ${ }^{5}$ Department of Medical Biology, University of Melbourne, Parkville, Australia and ${ }^{6}$ Academy of Immunology and Microbiology, Institute for Basic Science, Pohang University of Science and Technology, Pohang 790-784, Republic of Korea. Correspondence: KE Webster (k.webster@garvan.org.au) 
pathways and are then distributed differently in the periphery, raises questions about their ensuing maintenance. Homeostasis of NKT cells was found to require IL-15, however NKT17 cells had yet to be identified at this time. ${ }^{17,18}$ In the first study to examine pLN NKT cells, it was found that IL-15R $\beta$ expression was very low on NK1.1-negative cells. ${ }^{8}$ This was later shown to also be the case for thymic ROR $\gamma \mathrm{t}^{+} \mathrm{NKT}$ cells ${ }^{16}$ and splenic $\mathrm{IL}^{-17 \mathrm{RB}^{+}}$NKT cells (of which ROR $\gamma \mathrm{t}^{+}$are a subset). ${ }^{19}$ Interestingly, in mice with a mutant form of IL-15, the IL-17RB ${ }^{-}$cells are the most significantly decreased. ${ }^{19}$ These observations strongly suggest that ROR $\gamma \mathrm{t}^{+}$NKT17 cells do not share the same level of dependency on IL-15 as other NKT cells. Consequently, the factors that maintain this population in the periphery are unknown.

Here we show that, in contrast to the bulk of NKT cells, the homeostasis of IL-17-producing ROR $\gamma \mathrm{t}^{+} \mathrm{NKT}$ cells depends on IL-7 rather than IL-15. After exposure to IL-7, NKT17 cells rapidly initiate cellular proliferation, without the need for TCR-CD1d contact. This activation requires the phosphoinositide 3-kinase (PI3K)/AKT/mTOR signaling pathway and is precisely tuned to the density of cell surface IL-7R $\alpha$. Such dense receptor expression allows NKT17 cells to compete successfully for an "in-demand" cytokine, and would enable them to take advantage of the low levels of locally produced IL-7 at nonlymphoid sites such as the lung and the skin. These survival requirements indicate that $\mathrm{ROR} \gamma \mathrm{t}^{+}$NKT17 cells share a resource niche with differentiated $\mathrm{CD}^{+}$Th17 cells and $\mathrm{ROR} \gamma \mathrm{t}^{+}$innate lymphoid cells, and suggest IL-7R antagonism as a potential treatment for IL-17-driven pathology.

\section{RESULTS}

\section{IL-15 has no role in ROR $\gamma \mathrm{t}^{+}$NKT17 cell homeostasis}

To investigate the role of IL-15 in homeostasis of NKT17 cells, we first analyzed the expression of the IL-15R $\beta$, CD122. In agreement with previous findings, $8,16,19$ we observed that NKT17 cells, contained within the CD4 ${ }^{-} \mathrm{NK} 1.1^{-}$subset or directly analyzed by ROR $\gamma \mathrm{t}$ (Figure 1a,b), had minimal expression of CD122, suggesting decreased sensitivity to IL-15. IL-15 is predominantly delivered to cells via transpresentation, whereby IL- $15 \mathrm{R} \alpha$ expressed on monocytes, dendritic cells, and parenchymal cells binds and presents IL-15 to target cells, including NKT cells. ${ }^{20,21}$ In order to not discount any potential effect of cis-presentation, we also examined IL-15R $\alpha$ on NKT cells, but found that it was only expressed at very low levels, and did not differ between ROR $\gamma \mathrm{t}$ subsets (see Supplementary Figure S1 online).

In line with the variable expression of CD122, we found that IL-15-deficient mice had a significant increase in the proportion of IL-17-producing and ROR $\gamma \mathrm{t}^{+}$NKT cells (Figure 1c,d). Importantly, unlike total NKT cells, ${ }^{17}$ numbers of ROR $\gamma \mathrm{t}^{+}$ NKT cells were unchanged in IL-15-deficient mice, indicating that the dependence of NKT cells on IL-15 applies selectively to ROR $\gamma$ t-negative cells (Figure 1d).

To further evaluate the role of IL-15, we examined lymphopenia-driven proliferation of NKT cells in IL-15-deficient hosts. Proliferation of $\mathrm{ROR} \mathrm{t}^{-}$cells was limited, typical of slow homeostatic proliferation, and was reduced in IL-15 ${ }^{-1-}$ mice (Figure 1e), thereby confirming prior findings with unseparated NKT cells. ${ }^{17}$ In marked contrast, the ROR $\gamma \mathrm{t}^{+}$ subset proliferated rapidly, in both wild-type and IL-15 ${ }^{-1-}$ hosts, with slightly improved recovery in the latter, most likely due to reduced competition from ROR $\gamma \mathrm{t}^{-}$cells. These data indicate that, for lymphopenia-induced proliferation of NKT cells, IL-15 signaling is important only for ROR $\gamma \mathrm{t}^{-}$and not for ROR $\gamma \mathrm{t}^{+}$cells.

Interestingly, although CD122 forms part of the IL-2 receptor, sensitivity to IL-2 does not appear to be likewise affected, as measured by STAT5 phosphorylation and proliferation (see Supplementary Figure S1). We found that ROR $\gamma \mathrm{t}^{+}$NKT cells express higher levels of IL-2R $\alpha$ (CD25) than ROR $\gamma \mathrm{t}^{-}$NKT cells (see Supplementary Figure S1), which may counteract the low expression of CD122 to maintain IL-2 responsiveness.

\section{Preferential expansion of IL-17-producing NKT cells after in vivo IL-7 treatment}

IL-7, another common homeostatic cytokine, is reported to have either no role ${ }^{18}$ or a minor role ${ }^{17}$ in NKT-cell homeostasis. As ROR $\gamma \mathrm{t}^{+}$NKT cells were not considered in these studies, we re-examined the response of NKT cells to IL-7. Mice were injected with exogenous IL-7 in the form of cytokine/antibody complexes, ${ }^{22}$ with control mice receiving IL-2/IL-2 mAb. Cytokine production by purified NKT cells was assessed ex vivo. IL-2-expanded NKT cells showed enhanced production of a variety of Th1 and Th2 cytokines, but interestingly less IL-17, a result reminiscent of that observed with $\mathrm{CD} 4{ }^{+} \mathrm{T}$ cells. ${ }^{23} \mathrm{In}$ stark contrast, only IL-17 was significantly elevated after IL-7 treatment (Figure 2a). Likewise, intracellular cytokine staining showed that IL-7-expanded NKT cells displayed enhanced synthesis of IL-17 (Figure 2b).

This finding raised the question whether IL-7 signaling specifically stimulated IL-17 production or, alternatively, caused selective expansion of IL-17-producing cells. Examining this question showed that IL-7 injection did indeed cause a selective expansion of NKT17 cells, as contained within the $\mathrm{CD} 4^{-} \mathrm{NK} 1.1^{-}$subset or directly analyzed by ROR $\gamma \mathrm{t}$ (Figure 2c and Supplementary Figure S2). Within the $\mathrm{ROR} \gamma \mathrm{t}^{+}$subset, it was the $\mathrm{CD} 4^{-}$fraction that responded preferentially to IL-7. This preferential expansion to IL-7 was highly specific, as it could not be replicated with either IL-2 or IL-15 injections, with both but particularly IL-15, favoring the ROR $\gamma \mathrm{t}^{-}$subset (Figure 2d and Supplementary Figure S2).

\section{ROR $\gamma \mathrm{t}^{+}$NKT cells cannot proliferate or survive in the absence of IL-7}

Injection of exogenous IL-7 showed that this cytokine specifically targets ROR $\gamma \mathrm{t}^{+} \mathrm{NKT}$ cells for expansion. Likewise, $\mathrm{ROR} \gamma \mathrm{t}^{+}$NKT cells rapidly proliferate in lymphopenic hosts (an environment with elevated IL-7) as demonstrated in Figure 1e. As such, we questioned whether IL-7 is the cytokine responsible for the normal homeostasis and survival of these cells. 
a

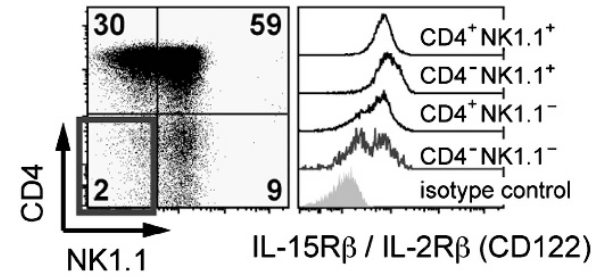

C
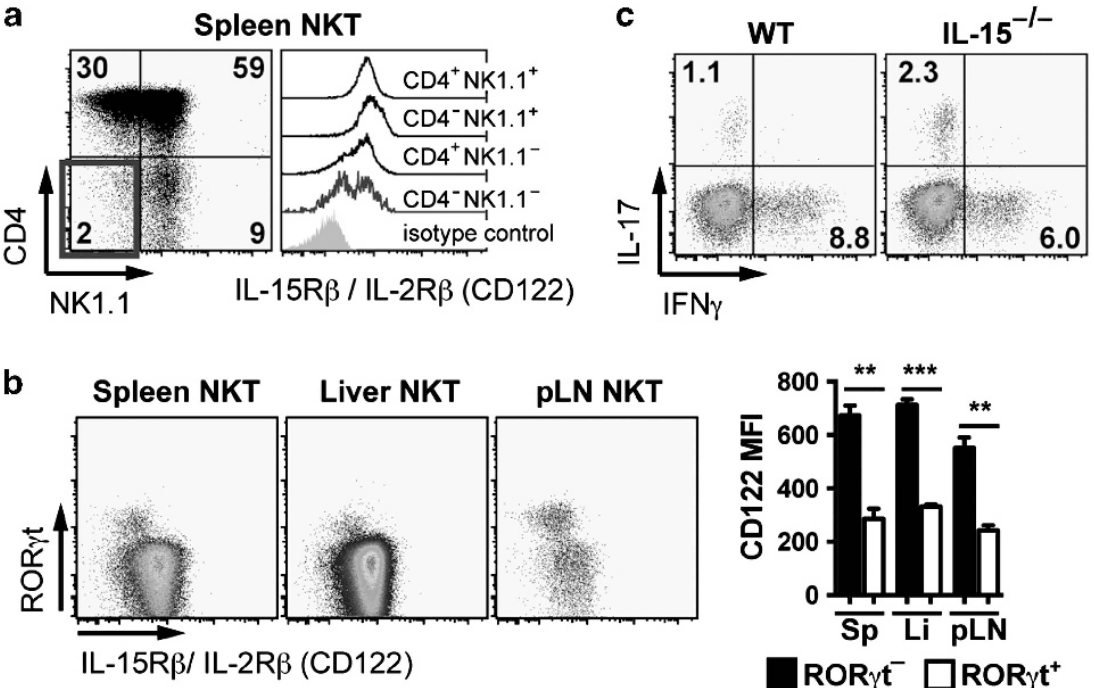

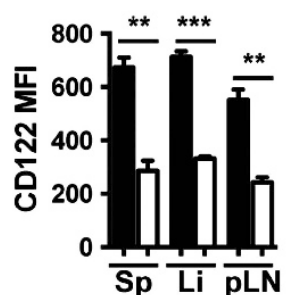

RORyt ${ }^{-} \square$ ROR $^{+} \mathbf{t}^{+}$

d
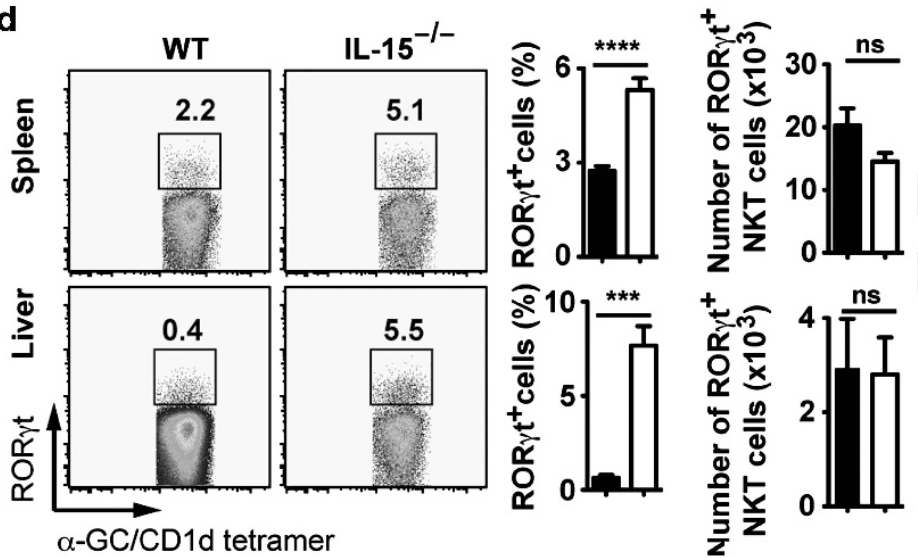

e
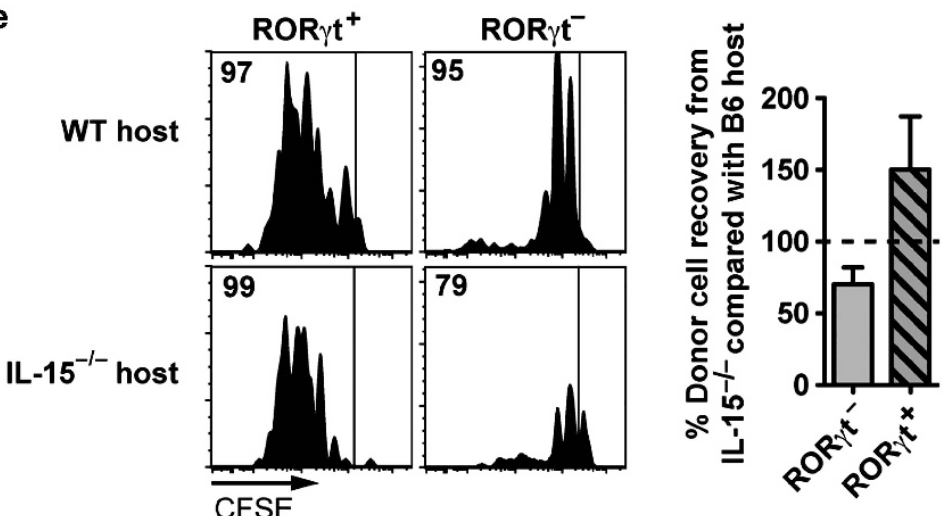

Figure $1 \mathrm{IL}-15$ does not support ROR $\gamma \mathrm{t}^{+}$NKT cell homeostasis. (a) Spleen NKT cells $\left(\alpha\right.$-GalCer/CD1d tetramer ${ }^{+} / \alpha \beta \beta_{\text {TCR }}{ }^{+}$) sub-divided by CD4 and NK1.1 by flow cytometry (left panel). Histograms depict surface expression of CD122 compared with isotype control (right panel). Box indicates subset associated with IL-17 production. (b) Expression of CD122 on spleen, liver, and pLN ROR $\gamma \mathrm{t}$ NKT subsets, shown as representative flow cytometry dot plots (left) and MFI (right). (c) Intracellular cytokine staining of electronically gated NKT cells from cultures of C57BL/6 wild-type (WT) and IL-15 ${ }^{-1-}$ spleen cells. (d) ROR $\gamma \mathrm{t}^{+}$NKT cells shown as percentage of total NKT cells and absolute number from spleen and liver of WT and IL-15 ${ }^{-1-}$ mice. (e) CFSE profiles of congenically marked NKT cells recovered from livers day 7 post-transfer into sublethally irradiated WT and IL-15 ${ }^{-1-}$ mice. ROR $\gamma \mathrm{t}$ subsets were electronically gated, depicted with cell divisions (left), and cell recovery in IL-15 1 - hosts as a percentage of cells recovered from WT hosts (dotted line at 100\%) (right). Data are representative of two to four independent experiments with two to three mice per group per experiment. Data in panel d are means \pm s.e.m. for WT $(n=13)$ and IL-15 ${ }^{-1-}(n=7)$ mice. Data in e right panel, includes data from three independent experiments with WT $(n=7)$ and IL-15 ${ }^{-1-}(n=5) .{ }^{* *} P \leq 0.01 ;{ }^{* \star *} P \leq 0.001 ;{ }^{* \star \star \star} P \leq 0.0001$. 


\section{a}

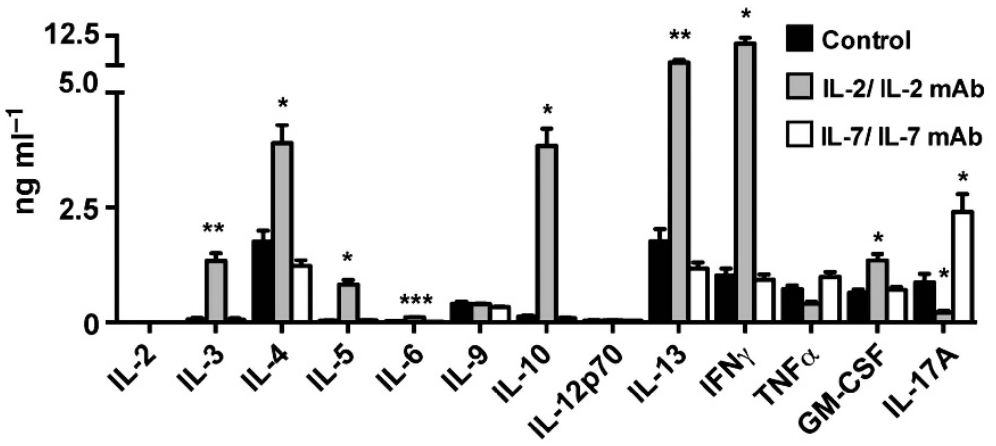

b
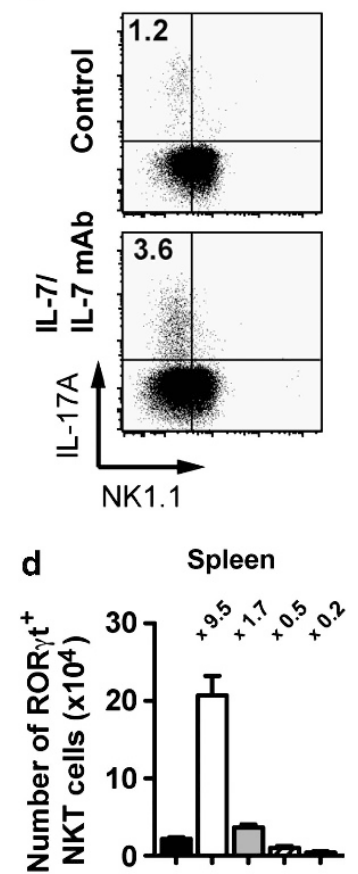

C
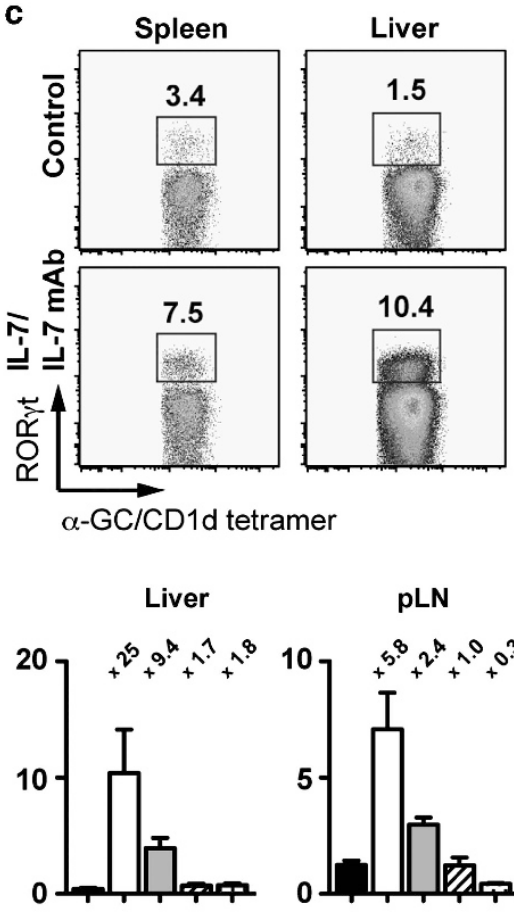

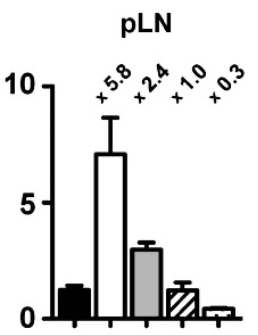

pLN

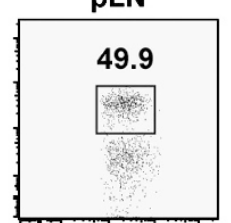

70.7

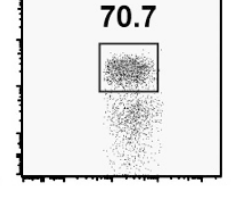

Ctrl

$\square^{\mathrm{IL}-7 / \mathrm{IL}-7 \mathrm{mAb}}$

$\square$ IL-2/ IL-2 mAb

(JES6-1)

$\square$ IL-2/ IL-2 mAb

(S4B6)

IL-15/

IL-15R $\alpha-F c$

Figure 2 IL-7 favors the expansion of IL-17-producing NKT cells. Mice were injected intraperitoneally (i.p.) with control PBS, IL-7/IL-7 mAb (M25), IL-2/ IL-2 mAb (JES6-1 or S4B6), or IL-15/IL-15R $\alpha \mathrm{Fc}(1 \mu \mathrm{g} / 5 \mu \mathrm{g})$ on days $-2,-1$, and 0 and analyzed as detailed below. (a) NKT cells were sorted from pooled spleens $(n=2-3)$ on day 3 post-in vivo treatment and cultured in wells coated with anti-CD3 $\left(10 \mu \mathrm{g} \mathrm{ml}^{-1}\right)$ and anti-CD28 $\mathrm{mAb}\left(10 \mu \mathrm{g} \mathrm{ml}{ }^{-1}\right)$ for $24 \mathrm{~h}$. Culture supernatants were analyzed using cytokine bead array. (b) Intracellular cytokine staining of electronically gated NKT cells from spleen cultures prepared on day 3 post-in vivo treatment. (c) Proportion of ROR $\gamma \mathrm{t}^{+}$cells in spleen, liver, and pLN NKT cells on day 5 post-in vivo treatment. (d) Absolute numbers of ROR $\gamma \mathrm{t}^{+}$NKT cells on day 5 post-in vivo treatment. Number above each column represents fold change compared with control. Data are representative of two to five independent experiments with two to three mice per group per experiment. Data are mean values \pm s.e.m. ${ }^{\star} P \leq 0.05$; ${ }^{* *} P \leq 0.01 ;{ }^{* * *} P \leq 0.001$ compared with control.

Genetic deletion of IL-7 renders mice severely lymphopenic, due to its broad role in lymphopoiesis and T-cell survival. ${ }^{24}$ IL- $7^{-1-}$ mice do have peripheral NKT cells, albeit in reduced numbers. ${ }^{17}$ Significantly, we found that the residual NKT cells were totally unable to synthesize IL-17, and instead were biased toward Th1 and Th2 cytokines, as shown by increased proportions of IFN $\gamma$ and IL-13 (Figure 3a). This suggests that either IL-7 offers NKT17 cells a functional advantage, or it is involved in their survival. Indeed we found that IL- $7^{-1-}$ mice have a profound and selective reduction in ROR $\gamma \mathrm{t}^{+}$NKT cells, being barely detectable by flow cytometry in the spleen, liver, and thymus (Figure $3 \mathbf{b}, \mathbf{c}$ ). Collectively, these findings indicate that IL-7 is obligatory for the development of the IL-17-producing $\mathrm{ROR} \gamma \mathrm{t}^{+}$subset of NKT cells.

The above experiments did not reveal whether IL-7 influences the survival of mature ROR $\gamma \mathrm{t}^{+}$NKT cells. To investigate this question, we examined lymphopenia-induced proliferation in

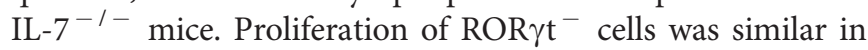
control and IL- $7^{-1}$ recipients, although recovery was reduced in the latter (Figure 3d). In marked contrast, an IL-7-deficient environment was clearly prohibitive for the ROR $\gamma \mathrm{t}^{+}$subset and led to reduced proliferation and negligible total recovery of the injected cells (Figure 3d). Hence, as for initial cell formation, the survival and homeostasis of mature ROR $\gamma \mathrm{t}^{+}$ NKT cells was critically dependent on contact with IL-7; 
a WT
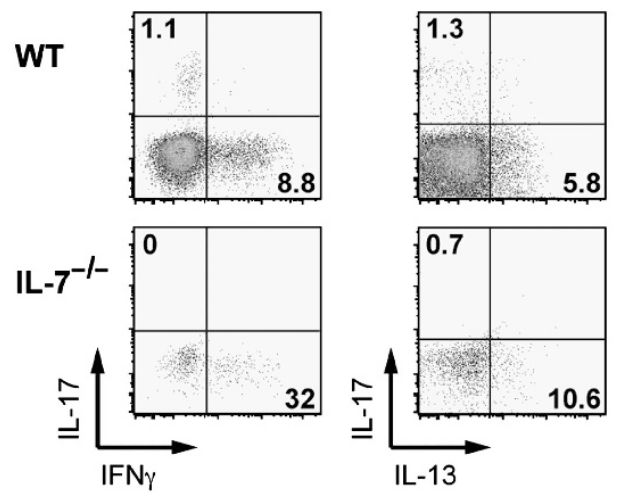

b
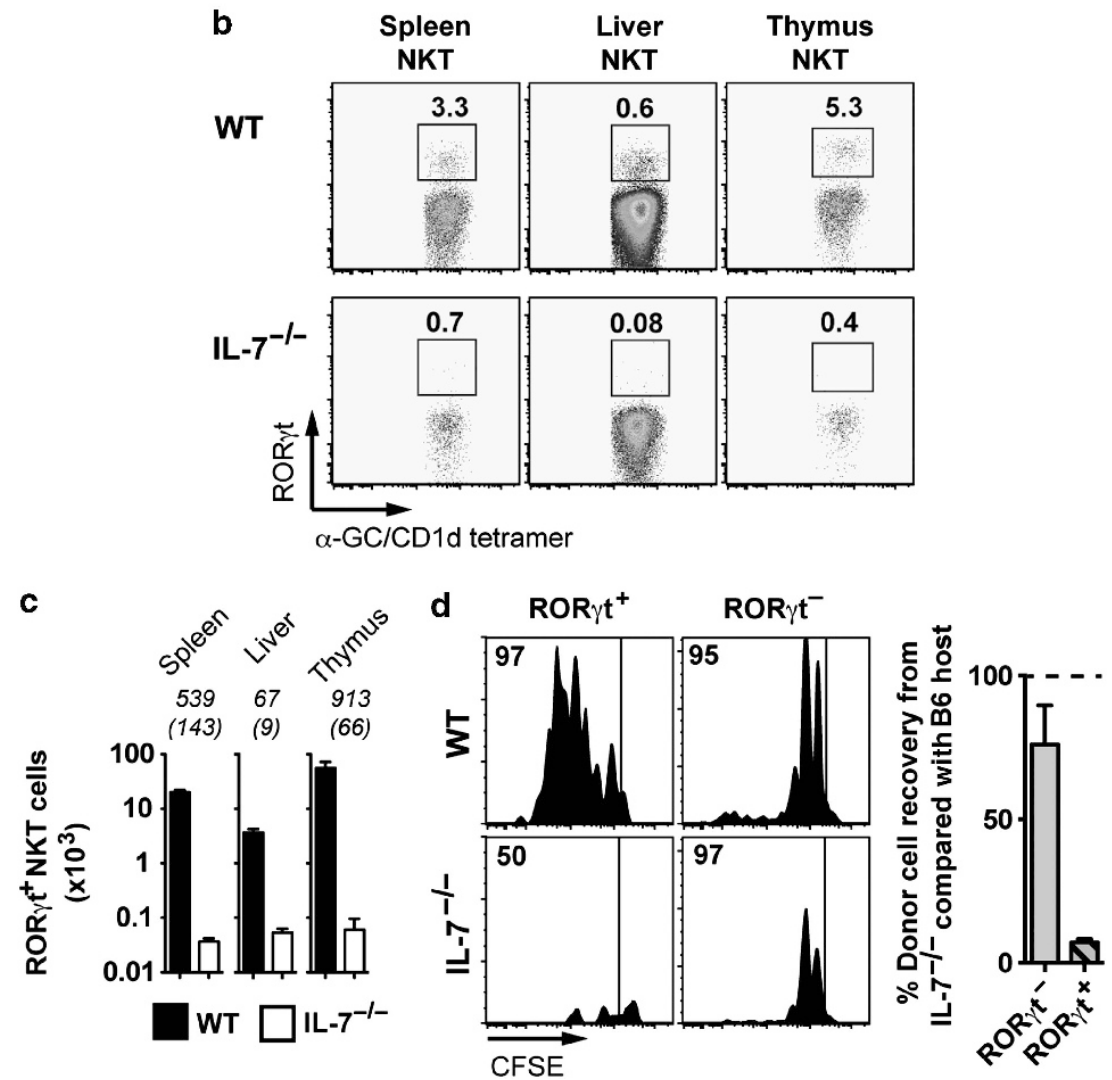

Figure $3 \mathrm{ROR} \gamma \mathrm{t}^{+} \mathrm{NKT}$ cells depend exclusively on IL-7 for survival. (a) Intracellular cytokine staining of electronically gated NKT cells from cultured WT and IL-7 ${ }^{-1-}$ spleen cells. (b) Proportion of ROR $\gamma \mathrm{t}^{+}$cells in spleen, liver, and thymus NKT cells from WT and IL-7 ${ }^{-1-}$ mice. (c) Absolute number of ROR $\gamma \mathrm{t}^{+}$NKT cells within the spleen, liver, and thymus of WT and IL-7 ${ }^{-1-}$ mice. Fold change in WT and IL- $7^{-1-}$ ROR $\gamma \mathrm{t}^{+}$NKT depicted above columns, with fold change of total NKT cell population depicted in brackets. (d) CFSE profiles of congenically marked NKT cells recovered from livers on day 7 posttransfer into sublethally irradiated WT and IL- $7^{-1-}$ mice. ROR $\gamma \mathrm{t}$ subsets were electronically gated from recovered cells, depicted with cell divisions (left) and cell recovery in IL-7 ${ }^{-1}$ hosts as a percentage of cells recovered from WT hosts (dotted line at $100 \%$ ) (right). Data are representative of two to three independent experiments with two to four mice per group per experiment. Data in panel b represent means \pm s.e.m. for WT $(n=13)$ and IL-7 ${ }^{-1}-(n=6)$ mice. For c, $n=6$ mice per group. Data in d, right panel, includes data from three independent experiments with WT $(n=7)$ and IL-7 ${ }^{-1-}(n=7)$.

contact with IL-15 was irrelevant (compare Figure 1e with Figure 3d; which were part of the same experiment).

Strong IL-7-driven expansion of ROR $\gamma \mathrm{t}^{+}$NKT cells is TCR independent and does not reflect enhanced signaling through STAT5 or STAT3

Like memory T cells, NKT-cell homeostasis is reported to be independent of TCR signaling. ${ }^{17}$ We found that this also applied to the ROR $\gamma \mathrm{t}^{+}$subset (Figure 4a). Stimulation of transferred NKT cells with IL-7/IL-7 mAb resulted in rapid proliferation of the $\mathrm{ROR} \gamma \mathrm{t}^{+}$subset, irrespective of CD1d availability.

As IL-7 signaling occurs through the Jak/STAT pathway and involves phosphorylation of STAT $5^{25}$ and STAT3, ${ }^{26}$ the high sensitivity of ROR $\gamma \mathrm{t}^{+}$NKT cells to IL-7 might reflect enhanced STAT phosphorylation. Although we found that IL-15 is more 


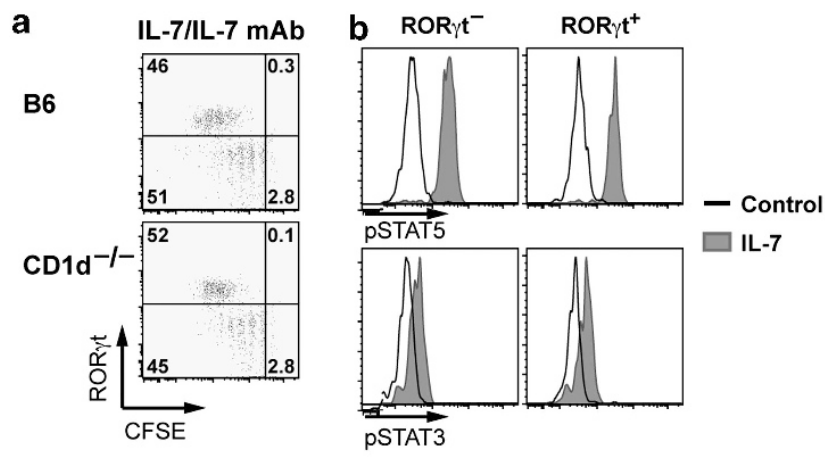

c

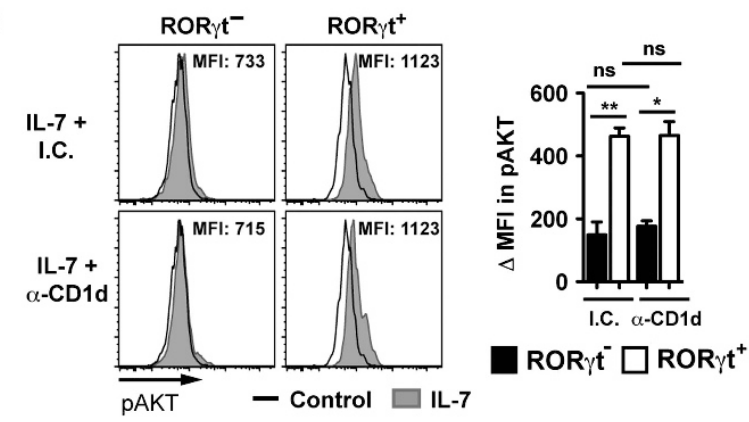

d

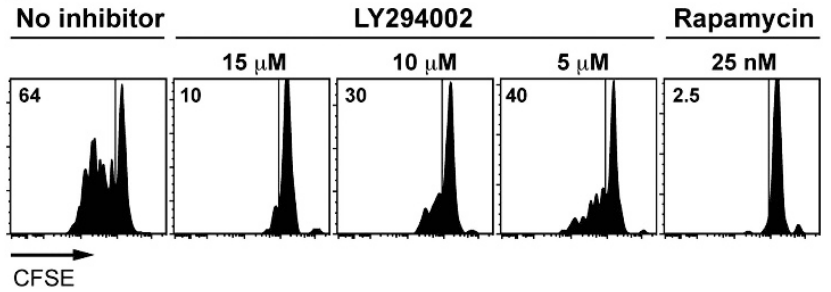

Figure 4 The role of TCR ligation, STAT signaling, and the PI3K/Akt/ mTOR pathway in IL-7-mediated NKT expansion. (a) CFSE profiles of congenically marked NKT cells recovered from livers of WT and CD1 ${ }^{-1-}$ mice one week after transfer. Mice were injected i.p. with IL-7/IL-7 mAb on days 1, 2, and 3. (b) Intracellular phosphorylation of STAT5 and STAT3 in electronically gated NKT cell subsets from pLN after stimulation with IL-7 (10 $\mathrm{ng} \mathrm{ml}^{-1}$ ) (shaded histograms) or unstimulated (open histograms). (c) Intracellular phosphorylation of AKT in NKT cells sorted from pooled spleen and pLN and cultured overnight with IL-7 and Rat IgG2b isotype control or IL-7 and anti-CD1d, as measured by flow cytometry; histograms (left) and $\triangle \mathrm{MFI}$ (right). ROR $\gamma \mathrm{t}^{+}$and $\mathrm{ROR} \gamma \mathrm{t}^{-}$cells electronically gated for analysis. (d) Proliferation of electronically gated ROR $\gamma \mathrm{t}^{+}$NKT cells sorted from pooled spleen and pLN, as measured by CFSE dilution, after $64 \mathrm{~h}$ culture with IL-7 and inhibitors. Data are representative of two to three independent experiments with at least two mice per group per experiment. For $\mathbf{c}, \Delta \mathrm{MFI}$ was calculated from three independent experiments. For $\mathbf{c}$ and d, cells were sorted from 5-10 mice and pooled for in vitro culture. Data are mean values \pm s.e.m. ${ }^{\star} P \leq 0.05 ;{ }^{\star \star} P \leq 0.01$ of ROR $\gamma \mathrm{t}{ }^{+}$compared with ROR $\gamma \mathrm{t}^{-}$cells.

effective at activating STAT5 in $\mathrm{ROR}_{\mathrm{t}}{ }^{-}$compared with ROR $\gamma \mathrm{t}^{+}$NKT cells, the inverse was not true for IL-7. After exposure to titrated concentrations of IL-7, STAT5 was rapidly phosphorylated in both ROR $\gamma \mathrm{t}^{+}$and ROR $\gamma \mathrm{t}^{-}$NKT cells to an equivalent degree (Figure $\mathbf{4 b}$ and Supplementary Figure S3). Likewise, both subsets showed equivalent sensitivity to STAT3 activation (Figure $\mathbf{4 b}$ ). These data imply that a preferential activation of the Jak/STAT pathway is not the mechanism by which IL-7 exerts its superior effects on ROR $\gamma \mathrm{t}^{+}$NKT cells.

\section{IL-7-mediated ROR $\gamma \mathbf{t}^{+}$NKT cell expansion requires} activation of the PI3K/AKT/mTOR pathway

Downstream effects of IL-7 ligation are often mediated by JAKSTAT signaling, however, the PI3K signaling pathway and inhibitory suppressor of cytokine signaling (SOCS) proteins also have a role. ${ }^{27,28}$ As such, the outcome of IL-7 ligation is influenced by several factors. In T cells, the PI3K pathway is primarily activated after engagement of TCR in conjunction with co-stimulatory receptors. ${ }^{29}$ Activation after IL-7 signaling alone is much slower in onset (hours rather than minutes), but can initiate cell-cycle entry. ${ }^{30}$ We examined PI3K-dependent signaling in purified NKT cells after overnight culture with IL-7. Notably, IL-7 led to far higher phosphorylation of AKT in the $\mathrm{ROR}_{\gamma \mathrm{t}}{ }^{+}$subset, without the need for TCR-CD1d interactions (Figure 4c). Further studies showed that IL-7induced proliferation of ROR $\gamma \mathrm{t}^{+}$cells was blocked by the PI3K inhibitor, LY294002, and also by the mTOR inhibitor, rapamycin (Figure 4d). These findings indicate that the strong IL-7-induced proliferation of ROR $\gamma \mathrm{t}^{+}$NKT cells is crucially dependent on the $\mathrm{PI} 3 \mathrm{~K} / \mathrm{AKT} / \mathrm{mTOR}$ signaling pathway.

\section{SOCS proteins are lower in ROR $\gamma \mathbf{t}^{+}$compared with ROR $\gamma \mathbf{t}^{-}$NKT cells}

As increased T-cell sensitivity to IL-7 has been associated with lower levels of SOCS1 and SOCS3 proteins, ${ }^{31,32}$ we asked whether the strong reactivity of ROR $\gamma \mathrm{t}^{+}$NKT cells to IL-7 might reflect altered levels of these molecules. Upon analysis, we found that compared with ROR $\gamma \mathrm{t}^{-} \mathrm{NKT}$ cells, the ROR $\gamma \mathrm{t}^{+}$ subset had significantly reduced levels of SOCS3 protein and Socs 3 gene expression (Figure 5a,b and Supplementary Figure S4). These data show that hyper-responsiveness to IL-7 correlates with a lower intrinsic expression of SOCS3.

\section{High IL-7R $\alpha$ expression is crucial for the strong proliferative response of ROR $\gamma \mathrm{t}^{+}$NKT cells}

As IL-7 is a limited resource, an enhanced capacity to bind this cytokine would offer a distinct advantage. Indeed we found that IL-7R $\alpha$ expression is higher on ROR $\gamma \mathrm{t}^{+}$than ROR $\gamma \mathrm{t}^{-} \mathrm{NKT}$ cells (Figure 5c). IL-7R $\alpha$ expression on ROR $\gamma \mathrm{t}^{+}$NKT cells was also much higher than on conventional $\mathrm{T}$ cells, e.g. $\mathrm{CD} 8{ }^{+} \mathrm{T}$ cells (Figure 5d), and correlated with the conspicuous proliferative response of ROR $\gamma \mathrm{t}^{+}$cells to IL-7 (Figure 5e).

The density of IL-7R $\alpha$ varies greatly amongst ROR $\gamma \mathrm{t}$ negative cells. With this in mind, we sorted pooled spleen and pLN into populations with low and intermediate-high expression of IL-7R $\alpha$ (Supplementary Figure S4) to directly test the effect of receptor density. Significantly, IL-7 induced stronger proliferation of IL-7R $\alpha^{\text {INT-HIGH }}$ than IL-7R $\alpha^{\text {LOW }}$ cells (Figure 5f). Hence, both for ROR $\gamma \mathrm{t}^{+}$and ROR $\gamma \mathrm{t}^{-}$cells, proliferative responses of NKT subsets to IL-7 correlated directly with surface levels of IL-7R.

\section{IL-7 alone does not induce or stabilize ROR $\gamma$ t expression in peripheral NKT17 cells}

Although not dependent on IL-7 for homeostasis, the moderate response of ROR $\gamma t^{-}$NKT cells to IL-7 led us to question the stability of the ROR $\gamma \mathrm{t}$ NKT lineage. Considering that 

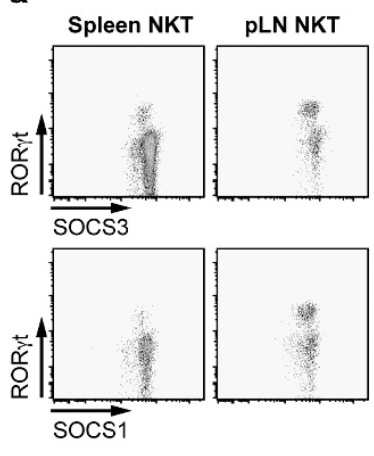

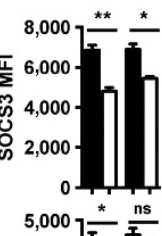
离 4,000 约, $3,000-$ \& 2,000 $0 \frac{1}{\mathrm{Sp}} \frac{\mathrm{T}}{\mathrm{pLN}}$ ROR $\gamma \mathrm{t}^{-} \square \mathrm{ROR} \gamma \mathrm{t}^{+}$ b

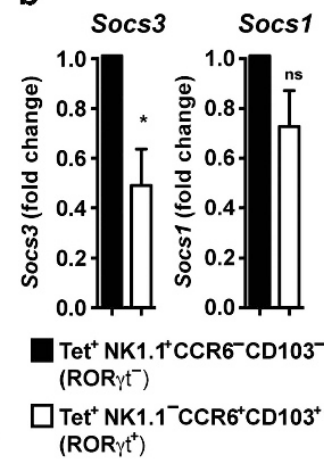

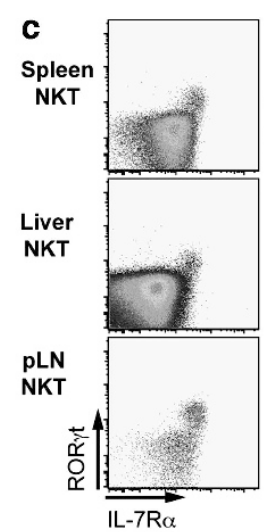

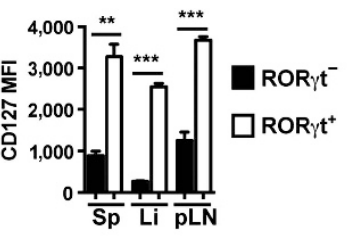

d PLN NKT

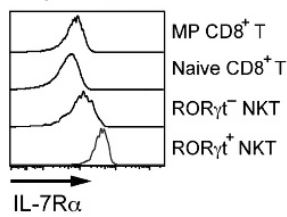

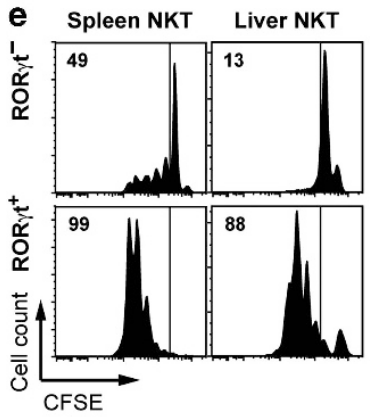

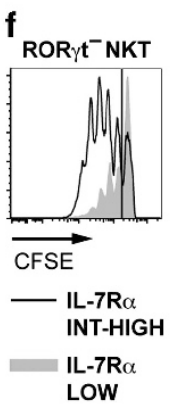

g

h
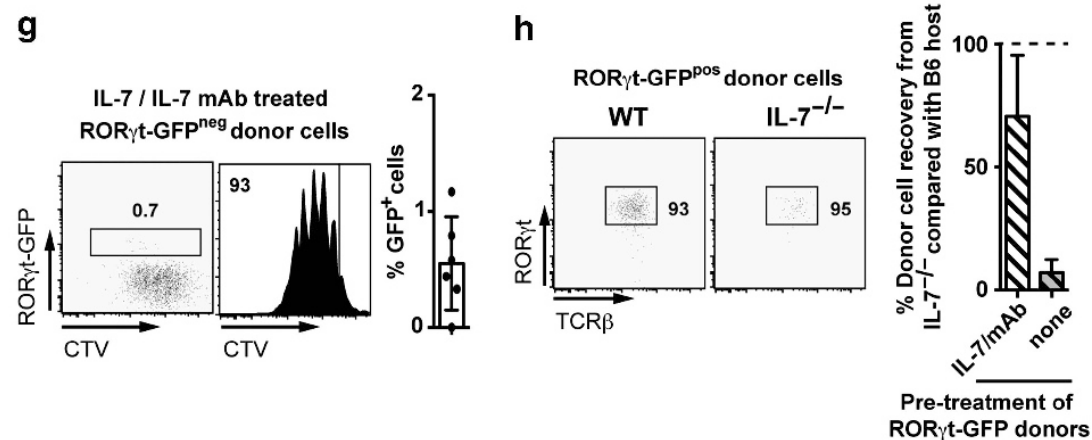

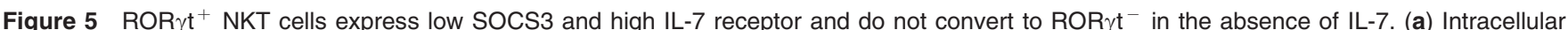
expression of SOCS3 and SOCS1 protein compared with ROR $\gamma$ t in NKT cells from the spleen and pLN, shown as representative flow cytometry dot plots (left) and MFI (right). (b) Socs1 and Socs3 mRNA expression of NKT subsets as evaluated by real-time PCR, normalized to Gapdh. Fold change of $\mathrm{NK} 1.1^{-} \mathrm{CCR}^{+}{ }^{+} \mathrm{CD} 103^{+}$subset relative to NK1.1 ${ }^{+} \mathrm{CCR}^{-}{ }^{-} \mathrm{CD} 103^{-}$subset. (c) Expression of IL-7R $\alpha$ on spleen, liver, and pLN ROR $\gamma \mathrm{NKT}$ subsets, shown as representative flow cytometry dot plots (left) and MFI (right). (d) Expression of IL-7R $\alpha$ on memory phenotype and naïve CD8 ${ }^{+} \mathrm{T} \mathrm{cells}, \mathrm{ROR} \mathrm{t}^{-}$, and ROR $\gamma \mathrm{t}^{+}$NKT cells from pLN. (e) In vitro proliferation of electronically gated NKT cells from spleen and liver as measured by CFSE dilution, after $72 \mathrm{~h}$ culture with IL-7. Proportion of divided cells shown. (f) Proliferation of purified IL-7R $\alpha$ intermediate-high and low expressors as measured by CFSE dilution after $72 \mathrm{~h}$ culture with IL-7. ROR $\gamma$ t was electronically gated upon analysis. (g) Sorted ROR $\gamma \mathrm{t}-\mathrm{GFP} \mathrm{P}^{\text {neg }}$ NKT cells analyzed for proliferation using CTV one week after transfer into congenic hosts injected with IL-7/IL-7 mAb on days 1-5. Percentage GFP ${ }^{+}$donor cells depicted in column graph. (h) ROR $\gamma \mathrm{t}$ expression of sorted ROR $\gamma$ t-GFP ${ }^{\text {pos }}$ NKT cells recovered from livers on day 8 post-transfer into sublethally irradiated WT and IL-7 ${ }^{-1-}$ mice (left). Cell recovery of transferred ROR $\gamma \mathrm{t}-$ GFP ${ }^{\text {pos }}$ NKT cells purified from mice pretreated with IL-7/LL-7 mAb or no treatment, depicted in IL-7 ${ }^{-1-}$ hosts as a percentage of cells recovered from WT hosts (dotted line at 100\%) (right). Data are representative of two to four independent experiments with at least two mice per group per experiment. Data in a represent means \pm s.e.m. with $n=5$ mice per group, representative of four experiments. ${ }^{\star} P \leq 0.05 ;{ }^{\star \star} P \leq 0.01$; ${ }^{* \star \star} P \leq 0.001$. For $\mathbf{b}, \mathbf{f}-\mathbf{h}$, cells were sorted from $5-10$ mice and pooled for experiments.

ROR $\gamma \mathrm{t}^{-}$NKT cells can be induced to make IL-17 in vitro, ${ }^{33}$ and innate lymphoid cell ROR $\gamma \mathrm{t}$ expression may be stabilized by IL-7, ${ }^{34}$ we questioned whether constant IL-7 or deprivation of this signal could induce a switch in ROR $\gamma \mathrm{t}$ expression in NKT cells. ROR $\gamma$ t-negative NKT cells were purified from ROR $\gamma$ t-GFP (green fluorescent protein) mice, ${ }^{35}$ labeled with Cell Trace Violet (CTV), and transferred into congenic B6 mice (Supplementary Figure S4). Following IL-7/IL-7 mAb treatment, cells again displayed moderate proliferation, but GFP was only detected in an average of $0.5 \%$ of donor cells (Figure 5g), indicating that even high-dose IL-7 was unlikely to induce conversion to $\mathrm{ROR} \gamma \mathrm{t}$.

We then purified $\mathrm{GFP}^{+}\left(\mathrm{ROR}_{\mathrm{t}}{ }^{+}\right)$NKT cells and transferred them into sublethally irradiated wild-type and IL- $7^{-1-}$ hosts. After 1 week, cell survival in IL- $7^{-1-}$ mice was poor, at only a fraction of that recovered from IL-7 replete mice (Figure 5h) and comparable to that of ROR $\gamma \mathrm{t}^{+}$cells recovered when bulk NKT cells were transferred (Figure 3d). Surviving donor cells retained their ROR $\gamma \mathrm{t}$ expression (Figure 5h), indicating that NKT17 cells do not "revert" to a ROR $\gamma \mathrm{t}$ negative state to survive in the absence of IL-7. Intriguingly, when donor mice were pre-treated with high-dose IL-7, subsequent survival of sorted ROR $\gamma \mathrm{t}^{+}$NKT cells in IL-7 ${ }^{-1-}$ mice was similar to that seen in an IL-7-competent environment (Figure 5h, right panel). This suggests that IL-7 can potentiate effects on NKT cells that remain long after exposure to the cytokine has ceased. This is reminiscent of the longlasting effects on $\mathrm{T}$ cells that has been reported for recombinant human IL-7 therapy. ${ }^{36}$ Collectively, these data support the concept that ROR $\gamma$ t-expressing NKT17 cells are a defined lineage, with distinct requirements for survival.

\section{DISCUSSION}

In order to uphold effective immune responses to an array of pathogens throughout a lifetime, the immune system must maintain its diverse cell types in both number and proportion. It is now known that immune cells are actively maintained by homeostatic mechanisms, that when removed, result in cell 
death. Conventional naïve T cells require a combination of IL-7 and TCR signaling from self-peptide MHC (major histocompatibility complex) ligands for survival. Maintenance of memory $\mathrm{T}$ cells however, is largely MHC independent, and depends on a mixture of IL-15 and IL-7. ${ }^{37}$

Likewise, NKT cells do not require contact with antigen to survive. ${ }^{17}$ Instead they were found to be primarily dependent on IL-15, with either only a minor role or no contribution from IL$7{ }^{17,18,38}$ We have now shown that ROR $\gamma \mathrm{t}$-expressing NKT17 cells depend entirely on IL-7. This absolute requirement for IL-7, and indifference to IL-15, means that these cells are not in competition for resources with the majority of NKT cells. Instead, the dependence on IL-7 reveals a shared characteristic with other IL-17-producing cells, as it has been recently found that Th17 cells ${ }^{31}$ and ROR $\gamma \mathrm{t}^{+}$innate lymphoid cells ${ }^{39}$ utilize IL-7 for their survival, while IL-17-producing $\gamma \delta \mathrm{T}$ cells ${ }^{26}$ also expand when exposed to IL-7.

Our data support the idea of NKT17 cells as a functionally and developmentally distinct lineage. The capacity to produce IL-17 stably resides with the thymic-derived ROR $\gamma \mathrm{t}^{+} \mathrm{NKT}$ subset, ${ }^{13}$ however a recent report suggested that ROR $\gamma \mathrm{t}$ negative NKT cells could be driven to produce IL-17 in vitro ${ }^{33}$ suggesting that some subset plasticity may exist. Interestingly, $\mathrm{ROR} \gamma \mathrm{t}$ fate-map mice have also revealed that $\mathrm{ROR} \gamma \mathrm{t}^{+}$innate lymphoid cells can downregulate $\mathrm{ROR} \gamma \mathrm{t}$, an event that is determined by the tissue environment and may in part depend on IL-7. ${ }^{34}$ In light of these findings, we asked whether IL-7 regulates ROR $\gamma \mathrm{t}$ expression, and thus lineage stability, rather than NKT17 survival. However, transfer of purified ROR $\gamma \mathrm{t}-$ GFP NKT cells revealed that these cells do indeed depend on IL-7 for survival, and cannot alter their phenotype to survive in its absence, at least in steady state conditions in the absence of antigenic or inflammatory cytokine challenge. Interestingly, the extended survival of cells pre-treated with IL-7/IL-7 mAb demonstrates that IL-7 can potentiate long-lasting effects. Whether or not this is the outcome of additional signaling events is under investigation.

Why are these IL-17-producing cells particularly sensitive to IL-7 signaling? Evidence from lymphopenic patients introduced the concept that IL-7 is produced constitutively, and is unaltered by external stimuli, characteristics that allow maintenance of a stable lymphocyte pool. ${ }^{40,41}$ This IL-7 is produced by stromal cells in the bone marrow, thymus, and lymph nodes, which allows lymphocytes developing in, or transiting through these tissues to receive survival signals. ${ }^{42}$ Intriguingly, early studies also detected IL-7 in non-lymphoid tissues, including the liver, ${ }^{43}$ keratinocytes, ${ }^{44}$ and intestinal epithelium. ${ }^{45}$ New reporter mice have now confirmed these findings, with IL-7 detected in the intestine, skin and liver, and also lung. ${ }^{46,47}$ Furthermore, there is evidence to suggest that this IL-7 production is not impervious to stimuli, but instead can be induced in response to bacterial signals. ${ }^{46,48,49}$ Considering that IL-17-producing cells, such as NKT17 cells, are enriched in barrier tissues and are important for defence at these locations, it is tempting to speculate that IL-7 at these sites, both steadystate and bacterial-induced, specifically supports NKT17 maintenance and rapid pathogen responsiveness. High-density IL-7R $\alpha$ on NKT17 cells would presumably help them compete for the limited IL-7 produced in these non-lymphoid tissues.

Although it is not clear why SOCS3 and not SOCS1 is significantly reduced in $\mathrm{ROR} \mathrm{t}^{+}$compared with $\mathrm{ROR} \gamma \mathrm{t}^{-}$ NKT cells, we hypothesize that this outcome may be somewhat similar to that seen in conventional $\mathrm{T}$ cells during virus infection. Upon exposure to IL-7, T cells in virus-infected animals were found to downregulate SOCS3 and not SOCS1. ${ }^{32}$ Considering that ROR $\gamma \mathrm{t}^{+}$NKT cells are acutely sensitive to IL-7 and require continual exposure to this cytokine to survive, we propose that this exposure leads to the observed downregulation of SOCS3.

In summary, we have determined that unlike conventional NKT cells, NKT17 cells do not require IL-15 for their survival. Instead, IL-7 is an indispensible homeostatic cytokine for NKT17 cells, which is more inline with other IL-17-producing cells, suggesting that functionally similar cells are both kept in balance, and can respond in concert to a pathogenic threat, by competition for a common resource (IL-7). This shared resource niche supports the idea of IL-7R antagonism as a potential approach for IL-17-driven pathology.

\section{METHODS}

Mice. C57BL/6 and B6.Ly5.1 mice were obtained from the Animal Resources Centre (Perth, Australia). IL- $7^{-1-}$, IL-15 ${ }^{-1-}$, and $\mathrm{CD} \mathrm{d}^{-1-}$ colonies were maintained at the Australian Bioresources Centre (Mossvale, Australia) and $\operatorname{Rorc}(\gamma \mathrm{t})^{\mathrm{GFP}}$ mice were maintained at The Walter and Eliza Hall Institute (Melbourne, Australia). Mice were used at 6-12 weeks of age. Animals were housed under conventional barrier protection and handled in accordance with the Garvan Institute of Medical Research and St Vincent's Hospital Animal Experimentation and Ethics Committee, which comply with the Australian code of practice for the care and use of animals for scientific purposes.

Flow cytometry. Cell suspensions of spleen, lymph nodes, and liver were prepared according to standard protocols and stained for FACS analysis using the following antibodies (eBioscience, San Diego, CA, unless stated): FITC-anti-NK1.1 (fluoroscein isothiocyanate-antiNK1.1) (PK136), CD122 (TM- $\beta 1$, BD Biosciences, Franklin Lakes, NJ), CD103 (2E7, Biolegend, San Diego, CA), and CD127(A7R34); AlexaFluor488-anti-phosphorylated-STAT5 (47/Stat5(pY694) and phosphorylated-STAT3 (4/P-STAT3(pY705) (BD Biosciences), and phosphorylated-AKT (Ser473,D9E, Cell Signaling, Danvers, MA); PEanti-ROR $\gamma(\mathrm{t})$ (B2D), IFN $\gamma$ (XMG1.2); PerCP-Cy5.5-anti-CD4 (RM45); biotinylated-anti-CD122 (TM- $\beta 1, \mathrm{BD}$ Biosciences), IL-15R $\alpha$ (R\&D Systems, Minneapolis, MN); APC-anti-TCR $\beta(H 57-597)$, CD127 (A7R34), and IL-17A (eBio17B7); Pe-Cy7-anti-CCR6 (29-2L17, Biolegend); Pacific Blue-anti-TCR $\beta(\mathrm{H} 57-597$, Biolegend), IL-17A (TC11-18H10.1, Biolegend), IFN $\gamma(X M G 1.2)$, and Pacific Blue streptavidin (Molecular Probes, Life Technologies, Carlsbad, CA); and Rat IgG2a and IgG2b Isotype Control FITC, biotin, and APC; Rabbit Isotype Control Alexa Fluor-488 (Cell Signaling), biotinylated-Goat Isotype Control (R\&D Systems). PE- or Brilliant Violet 421conjugated mouse CD1d tetramer loaded with $\alpha$-GalCer (Sapphire Biosciences or kindly provided by Professor Paul Savage, Brigham Young University, UT, USA) was produced in-house as previously described, ${ }^{50}$ using recombinant baculovirus encoding histaminetagged mouse CD1d and mouse $\beta 2$-microglobulin, originally provided by Professor Mitchell Kronenberg (La Jolla Institute for Allergy and Immunology, CA, USA). For detection of p-STAT5 and p-STAT3, cells were surface stained, stimulated with IL-7, IL-2, or IL-15 
(10 $\mathrm{ng} \mathrm{ml}^{-1}$ unless otherwise stated) for $10 \mathrm{~min}$ at $37^{\circ} \mathrm{C}$ (or overnight for p-AKT) then immediately fixed, permeabilized, and stained with pSTAT-5, p-STAT3, or p-AKT plus ROR $\gamma \mathrm{t}$ according to the manufacturer's instructions. To detect SOCS1 and SOCS3, fixed and permeabilized cells were stained with rabbit polyclonal anti-SOCS1 (ab3691) and SOCS3 (ab16030) (Abcam, Cambridge, England), followed by anti-rabbit FITC. Samples were analyzed on a CantoII or sorted using a FACSAria (BD Biosciences). Data were analyzed using FloJo software (Treestar, Inc., Ashland, OR).

Cytokine/mAb complexes. rmIL-2, IL-7, or IL-15 (Peprotech, Rocky Hill, NJ) were mixed with anti-IL-2 (JES6-1, eBioscience; S4B6, BD Biosciences) or anti-IL-7 mAb (M25, BioXCell, West Lebanon, NH) or IL-15 $\mathrm{R} \alpha / \mathrm{Fc}$ Chimera (R\&D Systems) and incubated at $37^{\circ} \mathrm{C}$ for 30 min as described. ${ }^{51}$ Mice were injected i.p. with $1 \mu \mathrm{g}$ cytokine $+5 \mu \mathrm{g}$ $\mathrm{mAb}$ on 3 consecutive days.

Cytokine measurement. Sorted NKT cells were stimulated with anti$\mathrm{CD} 3 / \mathrm{CD} 28\left(10 \mu \mathrm{g} \mathrm{ml}^{-1}\right)$ for $24 \mathrm{~h}$ at $37^{\circ} \mathrm{C}$, after which culture supernatant was assayed using BD Biosciences cytometric bead array flex set for mice. For intracellular cytokine staining, cells were incubated at $37^{\circ} \mathrm{C}$ in complete RPMI-1640 medium with phorbyl myristate acetate $\left(10 \mathrm{ng} \mathrm{ml}^{-1}\right)$ and ionomycin $\left(1 \mu \mathrm{g} \mathrm{ml}^{-1}\right)$ for $4 \mathrm{~h}$ with monensin. Intracellular staining was performed as per the manufacturer's protocol (BD Biosciences).

CFSE and CTV labeling. Lymphocytes were washed once in $0.1 \%$ BSA (bovine serum albumin) in PBS (phosphate-buffered saline), and labeled with $5 \mu \mathrm{M}$ (in vivo analysis) or $2.5 \mu \mathrm{M}$ (in vitro analysis) CFSE (Molecular Probes), or $10 \mu \mathrm{M}$ CTV (Molecular Probes) at a density of $1 \times 10^{7}$ cells per ml $0.1 \%$ BSA in PBS for $10 \mathrm{~min}$ at $37^{\circ} \mathrm{C}$ (CFSE) or 20 min at $22^{\circ} \mathrm{C}$ (CTV). The reaction was stopped with RPMI 10\% FCS and washed twice.

Adoptive cell transfers. Sorted congenic Ly5.1 ${ }^{+}$NKT cells were labeled with CFSE and injected intravenously into C57BL/6, IL-15 ${ }^{-1-}$, or IL- $7^{-1}$ recipient mice sublethally irradiated (550 RAD) 1 day before cell transfer, or non-irradiated $\mathrm{C} 57 \mathrm{BL} / 6$ or $\mathrm{CD} 1 \mathrm{~d}^{-1-}$ recipients. For analysis of homeostatic expansion, spleens and livers were harvested on day 7 and the Ly5.1 ${ }^{+}$donor cells quantified using flow cytometry. For analysis of CD1d dependence, mice were injected with IL-7/IL-7 mAb $(1 \mu \mathrm{g} / 5 \mu \mathrm{g})$ on days $1,2,3$, and anti-CD1d $(50 \mu \mathrm{g})$ or Rat IgG2b isotype control $\left(50 \mu \mathrm{g}\right.$ ) on days 1 and 3 (for CD1d ${ }^{-1}$ and C57BL/6, respectively). Livers were harvested on day 7 and Ly5.1 ${ }^{+}$ donor cells quantified using flow cytometry.

In vitro proliferation assay. Sorted NKT cells were CFSE labeled and cultured for $72 \mathrm{~h}$ with IL-7 (10 ng/ml). In some cases, cells were preincubated with inhibitors for $1 \mathrm{~h}$ before the addition of IL-7; LY294002 $(5,10$, and $15 \mu \mathrm{M})$ (Calbiochem, Darmstadt, Germany) and Rapamycin (25 nM) (Merck). After culture, cells were stained with ROR $\gamma \mathrm{t}$ antibody, and analyzed by flow cytometry.

Real-time PCR. RNA was isolated from sorted NKT cell subsets representative of $\mathrm{ROR} \mathrm{t}^{+}$and $\mathrm{ROR} \gamma \mathrm{t}^{-}$cells (pLN NK1.1 $\mathrm{CCR}^{+}{ }^{+} \mathrm{CD}_{103}{ }^{+}$cells and splenic or pLN NK1.1 ${ }^{+} \mathrm{CCR}^{-}{ }^{-} \mathrm{CD} 103^{-}$ cells), using Qiagen RNeasy Micro or Mini kits as per the manufacturer's instructions. RNA was reverse transcribed into cDNA using the Qiagen QuantiTect Reverse Transcription kit. Real-time PCR for the detection of Socs 1 mRNA and Socs 3 mRNA was performed using TaqMan gene expression assays (Mm00782550_s1*) and (Mm00545913_s1*) (Applied Biosystems, Life Technologies). Gapdh mRNA was used as an endogenous control. Samples were assayed on an ABI 7900 HT Real-Time PCR machine.

Statistical analysis. Results are presented as means \pm s.e.m. Experiments comparing wild-type and knockout mice were assessed using the Mann-Whitney $U$-test. Unpaired, two-tailed Student's $t$-test with bonferroni correction was used when performing multiple comparisons in Figure 2a (adjusted for two hypotheses). Paired $t$-tests were used to compare the MFI of ROR $\gamma \mathrm{t}^{+}$and ROR $\gamma \mathrm{t}^{-}$subsets. Statistical analyses were performed with Graphpad Prism 6.0b software (Graphpad), with differences considered statistically significant at $P<0.05$.

SUPPLEMENTARY MATERIAL is linked to the online version of the paper at http://www.nature.com/mi

\section{ACKNOWLEDGMENTS}

We thank the Biological Testing Facility (Garvan Institute) for animal breeding. We thank Robert Salomon and David Snowden for cell sorting, Amanda Hong for genotyping, and Marcin Ciula for CD1d tetramer preparation. This work was supported by National Health and Medical Research Council (NHMRC) Australia grants 1045647 (K.E.W.), 1011388 (J-H.C.), 454569/1013667 (D.I.G.), 1047903 (G.T.B), 1016953 (J.S.) and fellowships 1020770 (D.I.G.), 596805 (J.S.), and Australian Research Council Future Fellowship (G.T.B.).

\section{DISCLOSURE}

J.S. is a co-founder in a company for developing the therapeutic use of cytokine/mAb complexes. The authors have no other competing financial interests.

c) 2014 Society for Mucosal Immunology

\section{REFERENCES}

1. Kinjo, Y. et al. Invariant natural killer T cells recognize glycolipids from pathogenic Gram-positive bacteria. Nat. Immunol. 12, 966-974 (2011).

2. Brigl, M. et al. Innate and cytokine-driven signals, rather than microbial antigens, dominate in natural killer $\mathrm{T}$ cell activation during microbial infection. J. Exp. Med. 208, 1163-1177 (2011).

3. Zeissig, S. et al. Hepatitis B virus-induced lipid alterations contribute to natural killer $\mathrm{T}$ cell-dependent protective immunity. Nat. Med. 18, 1060-1068 (2012).

4. Coquet, J.M. et al. Diverse cytokine production by NKT cell subsets and identification of an IL-17-producing CD4-NK1.1- NKT cell population. Proc. Natl Acad. Sci. USA 105, 11287-11292 (2008).

5. Michel, M.L. et al. Identification of an IL-17-producing NK1.1(neg) iNKT cell population involved in airway neutrophilia. J. Exp. Med. 204, 995-1001 (2007).

6. Moreira-Teixeira, L. et al. Proinflammatory environment dictates the IL-17-producing capacity of human invariant NKT cells. J. Immunol. 186, 5758-5765 (2011).

7. Rachitskaya, A.V. et al. Cutting edge: NKT cells constitutively express IL-23 receptor and RORgammat and rapidly produce $\mathrm{LL}-17$ upon receptor ligation in an IL-6-independent fashion. J. Immunol. 180, 5167-5171 (2008).

8. Doisne, J.M. et al. Skin and peripheral lymph node invariant NKT cells are mainly retinoic acid receptor-related orphan receptor (gamma)t + and respond preferentially under inflammatory conditions. J. Immunol. 183, 2142-2149 (2009).

9. Doisne, J.M. et al. Cutting edge: crucial role of IL-1 and IL-23 in the innate IL-17 response of peripheral lymph node NK1.1- invariant NKT cells to bacteria. J. Immunol. 186, 662-666 (2011).

10. Korn, T., Bettelli, E., Oukka, M. \& Kuchroo, V.K. IL-17 and Th17 Cells. Annu. Rev. Immunol. 27, 485-517 (2009).

11. Pichavant, M. et al. Ozone exposure in a mouse model induces airway hyperreactivity that requires the presence of natural killer T cells and IL-17. J. Exp. Med. 205, 385-393 (2008).

12. Price, A.E., Reinhardt, R.L., Liang, H.E. \& Locksley, R.M. Marking and quantifying IL-17A-producing cells in vivo. PloS one 7, e39750 (2012).

13. Michel, M.L. et al. Critical role of ROR-gammat in a new thymic pathway leading to IL-17-producing invariant NKT cell differentiation. Proc. Natl Acad. Sci. USA 105, 19845-19850 (2008).

14. Engel, I., Zhao, M., Kappes, D., Taniuchi, I. \& Kronenberg, M. The transcription factor Th-POK negatively regulates Th17 differentiation in Valpha14i NKT cells. Blood 120, 4524-4532 (2012). 
15. Enders, A. et al. ZBTB7B (Th-POK) regulates the development of IL-17producing CD1d-restricted mouse NKT cells. J. Immunol. 189, 5240-5249 (2012).

16. Havenar-Daughton, C., Li, S., Benlagha, K. \& Marie, J.C. Development and function of murine RORgammat + iNKT cells are under TGF-beta signaling control. Blood 119, 3486-3494 (2012).

17. Matsuda, J.L. et al. Homeostasis of V alpha $14 \mathrm{i}$ NKT cells. Nat. Immunol. 3 , 966-974 (2002).

18. Ranson, T. et al. IL-15 availability conditions homeostasis of peripheral natural killer T cells. Proc. Natl Acad. Sci. USA 100 2663-2668 (2003).

19. Watarai, H. et al. Development and function of invariant natural killer Tcells producing T(h)2- and T(h)17-cytokines. PLoS Biol. 10, e1001255 (2012).

20. Dubois, S., Mariner, J., Waldmann, T.A. \& Tagaya, Y. IL-15Ralpha recycles and presents IL-15 In trans to neighboring cells. Immunity 17, 537-547 (2002).

21. Castillo, E.F., Acero, L.F., Stonier, SW, Zhou, D \& Schluns, KS Thymic and peripheral microenvironments differentially mediate development and maturation of iNKT cells by IL-15 transpresentation. Blood 116, 2494-2503 (2010).

22. Boyman, O., Ramsey, C., Kim, D.M., Sprent, J. \& Surh, C.D. IL-7/anti-IL-7 $\mathrm{mAb}$ complexes restore $\mathrm{T}$ cell development and induce homeostatic T Cell expansion without lymphopenia. J. Immunol. 180, 7265-7275 (2008).

23. Yang, X.P. et al. Opposing regulation of the locus encoding IL-17 through direct, reciprocal actions of STAT3 and STAT5. Nat. Immunol. 12, 247-254 (2011).

24. von Freeden-Jeffry, U., Vieira, P., Lucian, L.A., McNeil, T., Burdach, S.E. \& Murray, R. Lymphopenia in interleukin (IL)-7 gene-deleted mice identifies IL-7 as a nonredundant cytokine. J. Exp. Med. 181, 1519-1526 (1995).

25. Carrette, F. \& Surh, C.D. IL-7 signaling and CD127 receptor regulation in the control of $\mathrm{T}$ cell homeostasis. Semin. Immunol. 24, 209-217 (2012).

26. Michel, M.L., Pang, D.J., Haque, S.F., Potocnik, A.J., Pennington, D.J. \& Hayday, A.C. Interleukin 7 (IL-7) selectively promotes mouse and human IL-17-producing gammadelta cells. Proc. Natl Acad. Sci. USA 109, 17549-17554 (2012).

27. Takada, K. \& Jameson, S.C. Naive T cell homeostasis: from awareness of space to a sense of place. Nat. Rev. Immunol. 9, 823-832 (2009).

28. Chong, M.M. et al. Suppressor of cytokine signaling- 1 is a critical regulator of interleukin-7-dependent CD8 + T cell differentiation. Immunity 18, 475-487 (2003).

29. Deane, J.A. \& Fruman, D.A. Phosphoinositide 3-kinase: diverse roles in immune cell activation. Annu. Rev. Immunol. 22, 563-598 (2004).

30. Lali, F.V., Crawley, J., McCulloch, D.A. \& Foxwell, B.M. A late, prolonged activation of the phosphatidylinositol 3-kinase pathway is required for Tcell proliferation. J. Immunol. 172, 3527-3534 (2004).

31. Liu, X. et al. Crucial role of interleukin-7 in T helper type 17 survival and expansion in autoimmune disease. Nat. Med. 16, 191-197 (2010).

32. Pellegrini, M. et al. IL-7 engages multiple mechanisms to overcome chronic viral infection and limit organ pathology. Cell 144, 601-613 (2011).
33. Monteiro, M., Almeida, C.F., Agua-Doce, A. \& Graca, L. Induced IL-17producing invariant NKT cells require activation in presence of TGF-beta and IL-1beta. J. Immunol. 190, 805-811 (2013).

34. Vonarbourg, C. et al. Regulated expression of nuclear receptor RORgammat confers distinct functional fates to NK cell receptor-expressing RORgammat (+) innate lymphocytes. Immunity 33, 736-751 (2010).

35. Eberl, G., Marmon, S., Sunshine, M.J., Rennert, P.D., Choi, Y. \& Littman, D.R. An essential function for the nuclear receptor RORgamma(t) in the generation of fetal lymphoid tissue inducer cells. Nat. Immunol. $\mathbf{5}$, 64-73 (2004)

36. Sportes, C. et al. Phase I study of recombinant human interleukin-7 administration in subjects with refractory malignancy. Clin. Cancer Res. 16, 727-735 (2010).

37. Surh, C.D. \& Sprent, J. Homeostasis of naive and memory Tcells. Immunity 29, 848-862 (2008).

38. Gordy, L.E. et al. IL-15 regulates homeostasis and terminal maturation of NKT cells. J. Immunol. 187, 6335-6345 (2011).

39. Satoh-Takayama, N. et al. IL-7 and IL-15 independently program the differentiation of intestinal CD3-NKp46 + cell subsets from Id2-dependent precursors. J. Exp. Med. 207, 273-280 (2010).

40. Fry, T.J. et al. A potential role for interleukin-7 in T-cell homeostasis. Blood 97, 2983-2990 (2001).

41. Napolitano, L.A. et al. Increased production of IL-7 accompanies HIV-1mediated T-cell depletion: implications for T-cell homeostasis. Nat. Med. 7, 73-79 (2001).

42. Link, A. et al. Fibroblastic reticular cells in lymph nodes regulate the homeostasis of naive T cells. Nat. Immunol. 8, 1255-1265 (2007).

43. Golden-Mason, L. et al. Expression of interleukin 7 (IL-7) mRNA and protein in the normal adult human liver: implications for extrathymic $T$ cell development. Cytokine 14, 143-151 (2001).

44. Heufler, C. et al. Interleukin 7 is produced by murine and human keratinocytes. J. Exp. Med. 178, 1109-1114 (1993).

45. Watanabe, M. et al. Interleukin 7 is produced by human intestinal epithelial cells and regulates the proliferation of intestinal mucosal lymphocytes. J. Clin. Invest. 95, 2945-2953 (1995).

46. Shalapour, S. et al. Commensal microflora and interferon-gamma promote steady-state interleukin-7 production in vivo. Eur. J. Immunol. 40, 2391-2400 (2010).

47. Repass, J.F. et al. IL7-hCD25 and IL7-Cre BAC transgenic mouse lines: new tools for analysis of IL-7 expressing cells. Genesis 47, 281-287 (2009).

48. Roye, O. et al. Dermal endothelial cells and keratinocytes produce IL-7 in vivo after human Schistosoma mansoni percutaneous infection. J. Immunol. 161, 4161-4168 (1998).

49. Sawa, Y. et al. Hepatic interleukin-7 expression regulates Tcell responses. Immunity 30, 447-457 (2009).

50. Matsuda, J.L. et al. Tracking the response of natural killer T cells to a glycolipid antigen using CD1d tetramers. J. Exp. Med. 192, 741-754 (2000).

51. Webster, K.E. et al. In vivo expansion of T reg cells with IL-2-mAb complexes: induction of resistance to EAE and long-term acceptance of islet allografts without immunosuppression. J. Exp. Med. 206, 751-760 (2009). 